\title{
Hematological Study of Spleenctomized Dog in Iraq
}

\author{
Ali Hussein Fadhil ${ }^{1}$, Mohammed Assad S. Alkabi ${ }^{1}$, Ihab Ghazi Mahdi AL, Shemmari ${ }^{2}$, \\ Ameer Sachet Atta AL-Saigh ${ }^{1}$ \\ ${ }^{1}$ Lecturer, ${ }^{2}$ Assist. Prof., Department of Veterinary Medicine/ Veterinary Medicine College, Iraq
}

\begin{abstract}
The effect of total and partial splenectomy on hematological value was studied on 12 healthy dogs, divided into two groups (A and B). The total splenectomy (group A) exhibited significant reduction $(\mathrm{P}<0.05)$ in $\mathrm{Hb}$, $\mathrm{PCV}$, and total RBC count but increase in ESR values. It also resulted in persistent increase in total leukocyte, neutrophil, and lymphocyte counts. In partial splenectomy produced non-significant effects on hematological parameters. No significant alteration in serum glucose or total protein concentration was observed after total or partial splenectomy.
\end{abstract}

Keywords: hematological value, splenectomy, dog, Iraq

\section{Introduction}

Spleen is a part of hemopotic and immune system, it is play a vital role in the lifespan of erythrocytes, and it is consider a major lymphoid organ and is located in the left cranial abdomen ${ }^{1}$. The function of spleen are storing and element the old red blood cells from blood stream as well as antigen surveillance of the blood and antibody production ${ }^{2}$. The surgical removal of the spleen is called Splenectomy which is performed for animals whose spleen has been affected by trauma or damaged by disease such as cancer, infections or some autoimmune diseases ${ }^{3}$. The most reasons of medical indication for splenectomy is a disease of hemopotic system .Splenectomy is carried out in dog with hemolytic anemia such as hereditary spherocytosis and autoimmune hemolytic anemia ${ }^{4}$. Camacho et al.,(2010) ${ }^{8}$ have been mentioned dogs undergo to splenectomy candidate to Babesia canis infection so that must be considered emergency clinical cases and often it was considered fatal in these animals therefor must be given preventive medications. Splenectomy has been identified as a one of important risk factor for the development of serious illness due to natural Babesiaosis in dog 22 Post splenectomy infections and sepsis, due to decrease the level of antibodies and phagocytes activity or thrombosis, due to rises of platelet production in blood have been reported as sides effect of Splenectomy ${ }^{7,12}$ 2 The regenerative anemia reveled due to elevate of reticulocyte count and exist of nucleated red blood cells ${ }^{8}$. Marques et al (2003) ${ }^{12}$ have been reported autologous spleen transplantation is a batter procedure after complete removed of spleen for maintenance the immune and hematopoietic functions of spleen. Mortimar. (2017) has been showed there was no abnormal postoperative decrease of erythrocyte, hemoglobin or hematocrit values, and regeneration occurred at the same level as in the control dogs. The differences in number of white blood cells with subsequent leukocytosis is showed in dog with splenectomy ${ }^{7,11}$ Initially transient neutrophilia is followed by the persistent lymphocytosis and monocytosis. The animals showed highly percentage of leukocytes parallel to the significant left shift, the myelocytes or other cells progenies of granulocytes often exist in blood circulation ${ }^{14,21,25}$. A many researches on laboratory animals mentioned the amounts of spleen tissue aid to increase the ability of recovery function of spleen in auto transplantation of spleen ${ }^{11,16}$

\section{Material and Method}

\section{A- Animals}

Twelve healthy male's dogs aged $8^{\text {th }}$ months included in that study. A physical examination was made in all animals to chick their health status. All dogs were administrated antihelemantics and housed indoors in individual cages and kept under management and nutritional. The animals were randomly divided into two 
groups include of six dogs for each group, designated as group A and B.

\section{Surgical Operations}

Total and partial splenectomy were performed in animals of group 1 and 2, respectively in surgical lab in collage of veterinary medicine $\backslash$ Kerbala University following the standard anesthesia and surgical procedures ${ }^{5}$.

\section{Hematological Samples}

Blood samples with EDT A for complete blood analysis and without anticoagulant for serum chemistry profile were collected. A one sample was drawn from each animal. The first blood sample was drawn prior to surgical operation to obtain baseline values. The other samples were obtained weekly, starting on week $1^{\text {st }}$ to week 12th post-operative.

\section{Result and Discussion}

Results of hematological study.

Results of erythrocytes
All dogs in the study remained apparently healthy during the trial period. None of the dogs in both groups suffered any post-surgical complication, such as hemorrhage or peritonitis. Several changes in blood components was identified that persisted for a variable periods following total or partial splenectomy (Table 1). A persistent anemia was observed in animals of group $\mathrm{A}$, as noted by a significant reduction $(\mathrm{P}<0.05)$ in $\mathrm{RBC}$ count, $\mathrm{Hb}$ cone. and $\mathrm{PCV}$ values on 3 th, 4 th, $5^{\text {th }}$ and $6^{\text {th }}$ week post-surgery, as compared to their control values and with group B. The anemia in total splenectomized dogs could be related to loss of the spleen-iron regulatory function as reported in man by earlier workers, this agree with Sipka et al( 2006) which mentioned the significant decrease of red blood cells values and long postoperative recovery after total splenectomy have been recorded in dog.

A significant $(\mathrm{P}<0.05)$ increase in ESR values was observed in animals of both groups, respectively, compared to their control values. However, among groups there was non-significant difference . this higher ESR values might be associated with persistence anemia and has also been explained by Benjamin (2000).

Table 1. The latter's referred to differences in erythrocytes parameters between group (A) and group (B) at $\mathrm{P}=\mathbf{0 . 0 5}$.

\begin{tabular}{|c|c|c|c|c|c|c|c|c|c|c|c|c|c|}
\hline \multicolumn{3}{|c|}{ Pre-operative } & \multicolumn{11}{|c|}{ Post-operative } \\
\hline Group & Week & 0 & 1 & 2 & 3 & 4 & 5 & 6 & 7 & 8 & 9 & 10 & 11 \\
\hline \multirow[t]{8}{*}{ A } & $\mathrm{RBC}$ & 5.98 & 4.1 & 4.08 & 4.02 & 3.98 & 3.86 & 4.08 & 4.28 & 4.06 & 3.97 & 4.13 & 4.23 \\
\hline & & A & A & A & A & A & A & A & A & A & A & A & A \\
\hline & $\mathrm{Hb}$ & 14.2 & 11.8 & 11.8 & 12.1 & 10.8 & 9.9 & 11.2 & 11 & 10.7 & 12 & 12.4 & 12 \\
\hline & & A & A & A & A & A & A & A & A & A & A & A & A \\
\hline & PCV & 40 & 39.2 & 28.2 & 28.7 & 27 & 29 & 29.5 & 30.2 & 29.7 & 29.6 & 30.8 & 30.3 \\
\hline & & A & A & A & A & A & A & A & A & A & A & A & A \\
\hline & ESR & 8.2 & 35.2 & 33.3 & 36.5 & 40.5 & 39 & 34.2 & 32.7 & 35.3 & 29.7 & 31.8 & 37.7 \\
\hline & & A & A & A & A & A & A & A & A & A & A & A & A \\
\hline Group & RBC & 6.46 & 5.55 & 5.62 & 5.65 & 5.72 & 5.83 & 5.98 & 6.06 & 6.08 & 6.04 & 5.95 & 6 \\
\hline B & & B & B & B & B & B & A & B & B & B & B & B & B \\
\hline & $\mathrm{Hb}$ & 14.5 & 14 & 14.4 & 14.7 & 14.1 & 14.5 & 15.4 & 15.2 & 15.2 & 15 & 14.8 & 15.4 \\
\hline & & B & B & B & B & B & B & B & B & B & B & B & B \\
\hline
\end{tabular}


Cont... Table 1. The latter's referred to differences in erythrocytes parameters between group (A) and group (B) at $\mathrm{P}=\leq \mathbf{0 . 0 5}$.

\begin{tabular}{|l|l|l|l|l|l|l|l|l|l|l|l|l|l|}
\hline & PCV & 39 & 38.2 & 38.8 & 44 & 37.2 & 39.2 & 39.6 & 39.8 & 37.7 & 37.5 & 37 & 38.4 \\
\hline & & A & A & B & B & B & B & B & B & B & B & B & B \\
\hline & ESR & 9.5 & 32.5 & 30.5 & 29.6 & 29.2 & 28 & 29.4 & 28.4 & 28.3 & 28.2 & 27.5 & 26.8 \\
\hline & & B & B & B & B & B & B & B & B & B & A & B & B \\
\hline
\end{tabular}

\section{Results of leukocytes}

A significant $(\mathrm{P}<0.05)$ increase in total leukocyte, neutrophil, lymphocyte, and eosinophil counts, a transient increase in monocyte, were observed post-operatively in group A dogs compared to control values and with group B dogs (Figs.3). Modifications in these blood cells could be coupled with total splenectomy and its predisposition for transient and intermittent type of nonspecific bacteremia or septicemia 23.

\begin{tabular}{|c|c|c|c|c|c|c|c|c|c|c|c|c|c|}
\hline \multicolumn{3}{|c|}{ Pre- operative } & \multicolumn{11}{|c|}{ Post-operative } \\
\hline Group & Week & 0 & 1 & 2 & 3 & 4 & 5 & 6 & 7 & 8 & 9 & 10 & 11 \\
\hline \multirow[t]{12}{*}{ A } & TLC & 8.2 & $14.5 \mathrm{~A}$ & 14.4 & 14.6 & 14.6 & 14.4 & 14.6 & 14.4 & 14 & 15 & 14.6 & 14 \\
\hline & & A & & A & A & A & A & A & A & A & A & A & A \\
\hline & $\mathrm{N}$ & 4883 & 8465 & 8709 & 7549 & 7578 & 8254 & 8656 & 7645 & 7925 & 8661 & 8574 & 8560 \\
\hline & & A & A & A & A & A & A & A & A & A & A & A & A \\
\hline & $\mathrm{L}$ & 2477 & 3863 & 3175 & 3424 & 3664 & 3980 & 3974 & 4332 & 4025 & 4223 & 4034 & 4055 \\
\hline & & A & A & A & A & A & A & A & A & A & A & A & A \\
\hline & M & 365 & 738 & 879 & 629 & 308 & 332 & 448 & 426 & 438 & 665 & 490 & 473 \\
\hline & & & A & A & A & A & A & A & A & A & A & A & A \\
\hline & E & 595 & 138 & 1635 & 2429 & 1669 & 1747 & 1591 & 1747 & 1533 & 1379 & 1350 & 1355 \\
\hline & & A & A & A & A & A & A & A & A & A & A & A & A \\
\hline & B & 68 & 44 & 27 & 20 & 77 & 95 & 30 & 24 & 23 & 61 & 48 & 30 \\
\hline & & A & A & A & A & A & A & A & A & A & A & A & A \\
\hline Group & TLC & 8.7 & 9.8 & 9.4 & 9.4 & 8.9 & 9.2 & 9 & 10.3 & 9.3 & 9.1 & 9.5 & 9.7 \\
\hline \multirow[t]{6}{*}{ B } & & A & B & B & B & B & B & B & B & B & B & B & B \\
\hline & $\mathrm{N}$ & 5383 & 5893 & 5839 & 5282 & 5498 & 5449 & 5269 & 3951 & 5250 & 5195 & 5415 & 5410 \\
\hline & & B & B & B & B & B & B & B & B & B & B & B & B \\
\hline & L & 2117 & 2471 & 2300 & 2660 & 2328 & 2683 & 2362 & 3143 & 3227 & 2993 & 3144 & 3514 \\
\hline & & B & B & B & B & B & B & B & B & B & B & B & B \\
\hline & $\mathrm{M}$ & 419 & 417 & 380 & 395 & 324 & 398 & 360 & 422 & 318 & 382 & 339 & 274 \\
\hline
\end{tabular}


Cont...

\begin{tabular}{|l|l|l|l|l|l|l|l|l|l|l|l|l|l|}
\hline & & A & B & B & B & A & A & B & B & B & B & B & B \\
\hline & E & 598 & 935 & 980 & 1230 & 857 & 673 & 682 & 752 & 606 & 478 & 607 & 547 \\
\hline & & A & B & B & B & B & B & B & B & B & B & B & B \\
\hline & B & 90 & 31 & 12 & 10 & 13 & 30 & 0 & 5 & 0 & 0 & 0 & 0 \\
\hline & & B & B & B & B & B & B & A & B & B & B & B & B \\
\hline
\end{tabular}

Table 2. The latter's referred to differences in leukocytes parameters between group (A) and group (B) at $\mathrm{P}=\leq \mathbf{0 . 0 5}$.

In healthy individual's bacteria are cleared off from circulation rapidly and effectively through phagocytosis by fixed tissues macrophages in the spleen and liver. Persistent bacteremia can occur when bacteria can multiply at a rate that exceeds the ability of the reticuloendothelial system to remove them (Dow and Jones, 2009). In addition, non-infectious factors such as corticosteroid excess caused by fear or other stresses, anesthesia,

laparotomy, or exercise may also be associated with moderate changes in leukogram ${ }^{17}$. In the present study all animals apparently remained clinically healthy throughout the study period and therefore, alteration in leukogram could be a normal body response. This is also supported by earlier reports indicating that a WBC count between 10,000 and $30,000 / \mu 1$ represents a moderate response to inflammation in $\operatorname{dogs}{ }^{18}$.

The presence of mild eosinophilia in dogs of group A has been a unique observation in the present study. Eosinophils are known to be an integral component of hypersensitivity and defense against certain parasites. In cat, eosinophilia has been reported to occur along with polycythemia and pernicious anemia after splenectomy 9. Similarly, leukocytosis has been reported in man and dog as a result of splenectomy and were attributed to an increase in neutrophils, lymphocytes, and eosinophils ${ }^{24}$

Therefore, it seems as the eosinophilia in the present study was either due to splenectomy or might have occurred as an influx of bone marrow reserve as seen in man. ${ }^{19}$

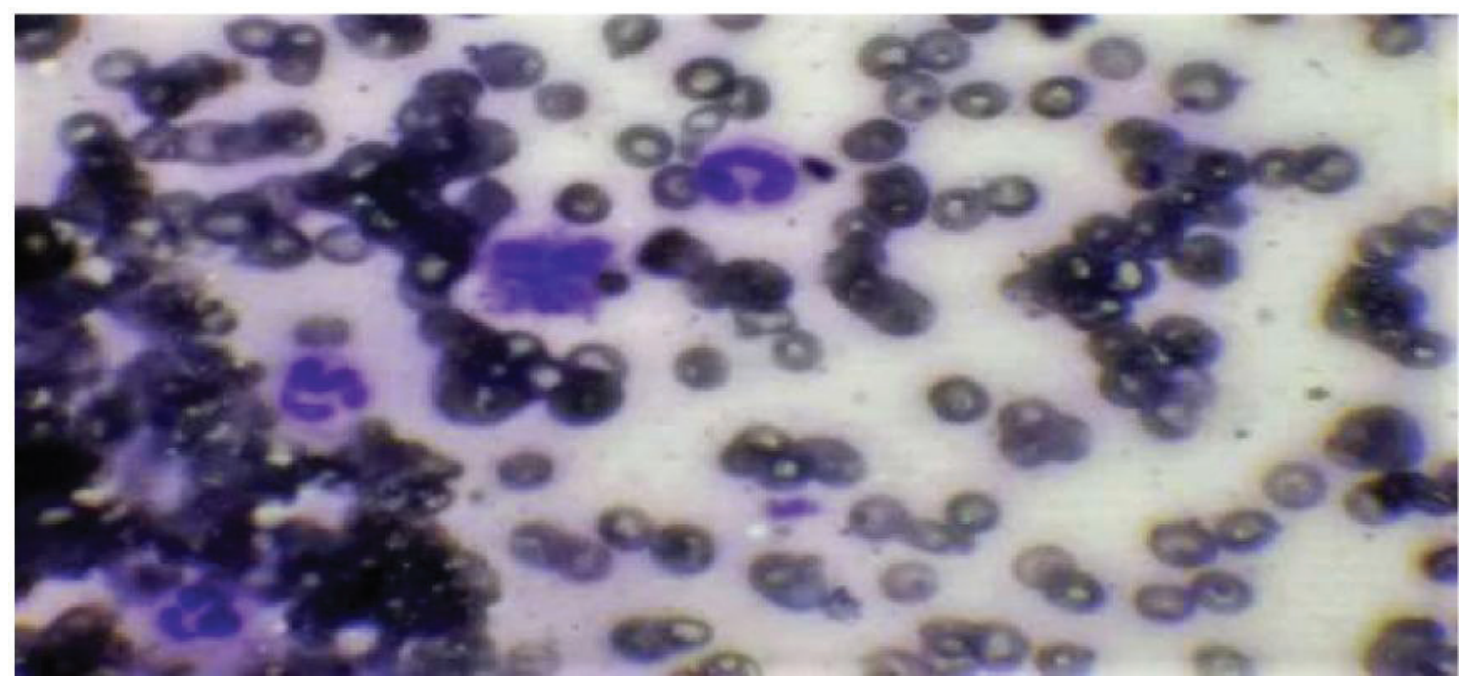

Fig (1) Band neutrophil in blood film of total spleenactomized dog 


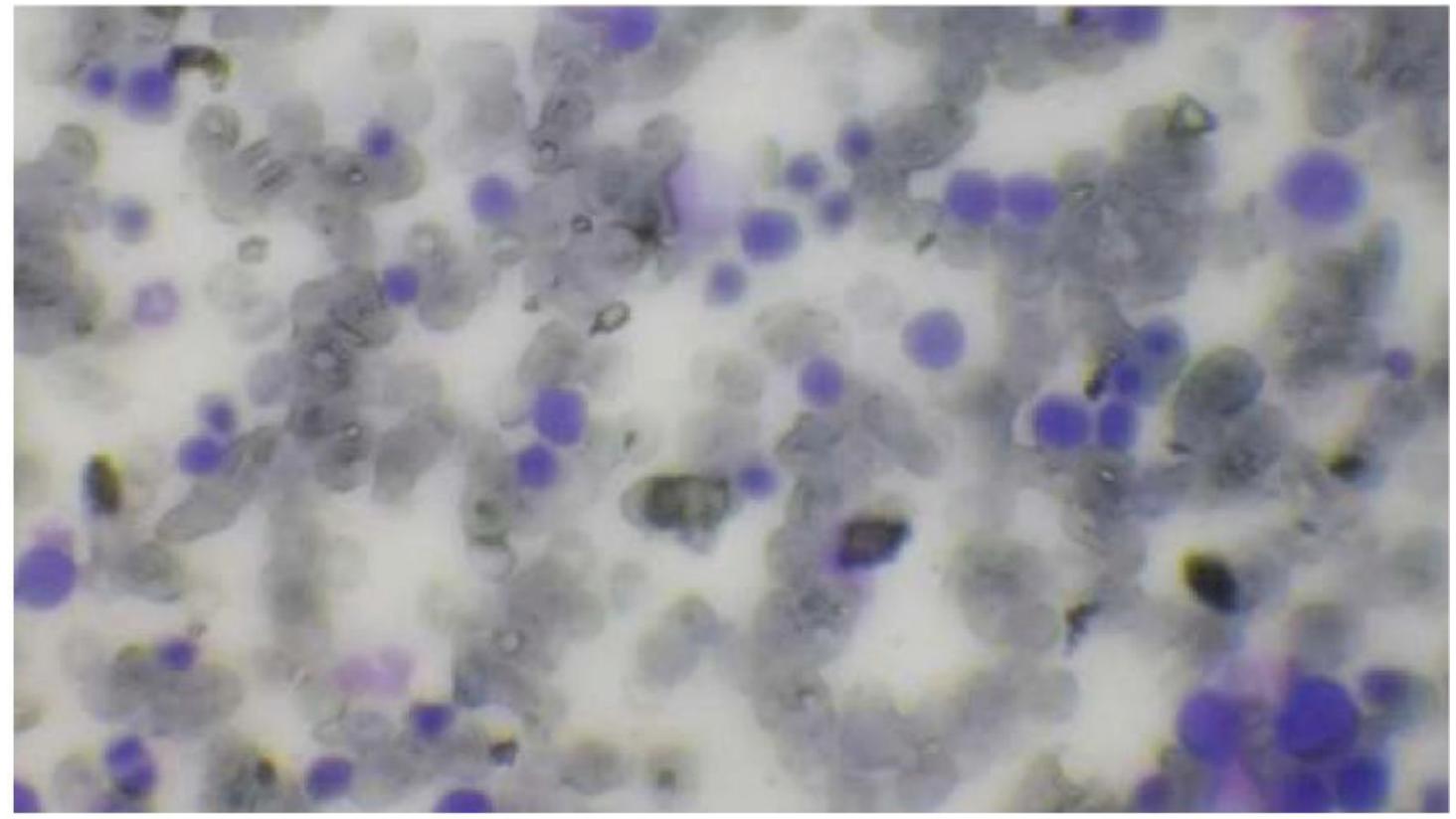

Fig (2) Lymphocytosis in blood film of total spleenactomized dog

From these results were concluded there was many significant differences in hematological parameters in erythrocytes and leukocytes in spleenactomized dog.

Financial Disclosure: There is no financial disclosure.

Conflict of Interest: None to declare.

Ethical Clearance: All experimental protocols were approved under the Department of Veterinary Medicine and all experiments were carried out in accordance with approved guidelines.

\section{References}

1. Nance D, Sanders V. Autonomic innervation and regulation of the immune system . Brain, Behavior, and Immunity 2007; 21(6): 736-745.

2. Imbert P, Rapp C, Buffet PA. Pathological rupture of the spleen in malaria: analysis of 55 cases (19582008). Travel Medicine and Infectious Disease. 2009; 7: 147-159.

3. Tillson D. Spleen. In: Textbook of Small Animal Surgery, Slatter, D.H, Ed., Saunders Co. LTd, Philadelphia. 2003: 1046-1062.

4. Rose AT, Newman MI, Debelak J. The incidence of splenectomy is decreasing: lessons learned from trauma experience. Am Surg. 2010; 66(5): 481-486
5. Archibald J. Canine Surgery. 2nd Ed. American Veterinary Publications, Santa Barbara, CA. U.S.A. 1974.

6. Benjamin M M. Outline of Veterinary Clinical Pathology. 3rd Ed. Iowa State Univ. Press, Ames, 1A., U.S.A. 2000.

7. Bessler H, Bergman M, Salman H, Beilin B, Djaldetti M. The relationship between partial splenectomy and peripheral leukocyte count. Journal of Surgical Research. 2004; 49-53.

8. Camacho AT, Pallas J, Gestal F. Olmeda Babesia canis infection in a splenectomized dog. Bull Soc Pathol Exot. 2010; 94: 1: 17-19.

9. Center S, JF Randolph HN. Eosinophilia in the cat: A retrospective study of 312 cases. J. Am. Ani. Hosp. Assoc. 2014; 26(4): 349-358.

10. Dow S, Jones RL. Bacteremia: Pathogenesis and diagnosis.Comp. Cont. Edu. 2009; 11(4): 432-443.

11. Karagülle E, Hoşcoşkun Z, Kutlu A. The effectiveness of splenic autotransplantation: an external study. Turkish Journal of Trauma \& Emergency Surgery. 2007; 13(1): 13-19.

12. Khan P, Nair R, Olivares J. Postsplenectomy reactive thombocytosis. Baylor University Medical Center Proceedings. 2009; 22: 9-12.

13. Kraus MD, Fleming MD, Vonderheide RH. The spleen as a diagnostic specimen. Cancer. 2009; 91(11). 
14. Labar B, Hauptmann E. Hematologija. Školska knjiga. 1998; 953-30598.

15. Marques R, Petroianu A, Coelho J. Bacterial phagocytosis by macrophage of autogenous splenic implant. Brazilian Journal of Biology. 2003; 63: 491495.

16. Miko I, Brath E, Nemeth N. Hematological, hemorheological, immunological, a $\mathrm{n}$ d morphological studies of spleen autotransplantation in mice: preliminary results. 2003.

17. Randy K. Interpreting the leukogram: Noninfectious factors that affect leukocyte production. Vet. Med. 2011; 86(5): 472-479.

18. Randy K. Interpreting neutrophil numbers. Vet. Med. 2013; 86(10): 975-982.

19. Resende, V. \& Petroianu, A. Functions of the splenic remnant after subtotal splenectomy for treatment of severe splenic injuries. The American Journal of Surgery. 2003; 185: 311- 315.

20. Sipka S, Bráth E, Tòth F. Distribution of peripheral blood cells in dog after splenectomy or autotransplantation. Microsurgery. 2006; 26: $43-$ 49.

21. Tang W, Wu F, Huang M, Friess H. Splenic tissue autotransplantation in rabbits: no restoration of host defense. Langenbecks Archives of Surgery. 2003; 9: 379-385.

22. TIZARD IR. Veterinary Immunology. W.B. Saunders, Philadelphia. 1996; 315-329.

23. Weinstein M, L Ruller, RJ Murphy. The clinical significance of positive blood Nculture: A comprehensive analysis of 500 episodes of bacteremia and fungemia in adults. 1. Laboratory and epidemiological observations. Rev. 2013.

24. Zahorec R. Ratio of neutrophil to lymphocyte counts - rapid and simple parameter of systemic inflammation and stress in critically ill. Bratislava Medical Journal. 2010; 102: 5-14.

25. Zhang H, Chen J, Kaiser G. The Value of Partial Splenic Auto-transplantation in Patients with Portal Hypertension. Archives of Surgery.2002; 137: 8993. 